\title{
MICHAEL APPLE E O CURRÍCULO: DA ESCOLA SEM PARTIDO À EDUCAÇÃO HOLÍSTICA
}

\author{
MICHAEL APPLE AND THE CURRICULUM: FROM SCHOOL WITHOUT HOLISTIC \\ EDUCATION
}

Leandro Luiz Lied ${ }^{1}$

\begin{abstract}
RESUMO: A disputa pelo controle do currículo dentro dos espaços da escola motiva pesquisadores, políticos, economistas e educadores a encontrar uma forma de se apropriar deste espaço em beneficio de seus interesses de classe. Michael Whitman Apple percebeu a importância deste debate e focou seu trabalho na análise da educação, do poder e da disputa do currículo entre as forças de direita, conservadora e da esquerda progressista/popular. Sob a ótica de Apple analisaremos a formação dos conceitos e ideologias que disputam os espaços da educação; a formação da nova direita; as propostas da escola sem partido e da educação integral; as disputas, no caso brasileiro, entre os defensores da Escola sem Partido e da proposta de reestruturação do Ensino Médio contrapondo um projeto de educação integral e holística baseada nas experiências do Pibid e do Pacto do Ensino Médio. Por fim, propormos uma nova forma de ver e de ser escola. Uma escola que responda as necessidades da sociedade e de seus jovens, uma escola que contemple a formação intelectual, que possibilite acesso a cultura, a práticas de cultivo do corpo e do espirito, que possibilite o desenvolvimento do ócio, que desenvolva as emoções, uma escola que contemple os novos paradigmas da humanidade: uma escola integral e holística.
\end{abstract}

Palavras-chave: Currículo. Michael Apple, escola sem partido, educação holística

\begin{abstract}
The struggle for control of the curriculum within school spaces motivates researchers, politicians, economists and educators to find a way to appropriate this space for the benefit of their class interests. Michael Whitman Apple realized the importance of this debate and focused his work on analyzing education, power and the curriculum dispute between right-wing, conservative and progressive / popular left forces. From Apple's point of view, we will analyze the formation of concepts and ideologies that compete in the spaces of education; the formation of the new right; the proposals of the school without party and integral education; the disputes, in the Brazilian case, between the defenders of the School without Party and the proposal of restructuring of High School, opposing a project of integral and holistic education based on the experiences of the Pibid and the Pact of Secondary Education. Finally, we propose a new way of seeing and being a school. A school that responds to the needs of society and its young people, a school that contemplates the intellectual formation, that allows access to culture, to practices of cultivation of the body and

\footnotetext{
1 Doutorando em Educação nas Ciências pela UNIJUI. Mestre em Teologia pela Pontifícia Universidade Católica do Rio Grande do Sul. Graduado em Filosofia pela Universidade de Passo Fundo. Endereço eletrônico: leandro_lied@hotmail.com
} 
spirit, that allows the development of leisure, that develops the emotions, a school that contemplates the new paradigms of humanity: an integral and holistic school.

Keywords: Curriculum. Michael Apple, non-party school, holistic education

\section{INTRODUÇÃO}

A questão do currículo vem alimentando o debate nos campos acadêmicos a mais de um século quando pedagogos europeus e norte-americanos se voltaram ao tema procurando entender como, que de forma organizada e cientificamente se poderia construir o conhecimento e de como esta organização poderia influenciar na formação do aluno estudante. A construção de uma teoria para designar este novo campo de estudo levou a elaboração de diversos olhares sobre o caminho que se percorre na construção do conhecimento.

Nesta reflexão, as elaborações de Michael Whitman Apple ${ }^{2}$ servirão como base para entender o campo de disputa do conhecimento, o contexto da elaboração do conhecimento e a atualidade do debate sobre o currículo da educação brasileira com as disputas pelo espaço escolar pelos grupos dominantes hegemônicos. As teorias de Apple sobre a análise relacional ou situacional contribuirão para o entendimento do espaço de disputa na educação básica no Brasil atual onde se estabeleceu uma batalha pelo espaço da escola entre os defensores de propostas dos campos sociais e os que defendem pensamentos neoconservadores e neofundamentalistas.

As concepções de escola sem partido e os processos desencadeados de reforma das bases curriculares da educação básica servirão como elemento de estudo de caso para exemplificar a construção de uma nova forma de ver a escola e a educação.

\footnotetext{
${ }^{2}$ Michael Whitman Apple nasceu nos Estados Unidos, em 1942. É descendente de imigrantes russos, membro de uma família pobre de trabalhadores. Desde cedo se engajou politicamente, primeiro no ambiente escolar e posteriormente no contexto acadêmico. Sua concepção pedagógica é fruto de sua convivência com um ambiente periférico e com um meio mais elitista, após a realização do mestrado e do doutorado no Teachers College da Columbia University. Como resultado deste contexto existencial elaborou sua pedagogia crítica, baseada na relação entre a educação e a sociedade, ou seja, na análise relacional ou situacional. Produtor de uma extensa obra, ele publicou, entre outros volumes, Ideologia e Currículo e Política Cultural e Educação. Neste último ele situa exemplarmente sua visão da educação inserida em um contexto social, na interação com as incontáveis faces da sociedade. Apple desenvolve um trabalho significativo, particularmente na esfera curricular do sistema educacional.
} 
Assim, buscando na tradição histórica da construção das teorias do currículo e refletindo sobre o momento de crise que passa a educação, cabe projetar novas formas e alternativas que possam refletir o pensamento do momento e apontar para a elaboração de novos paradigmas na educação brasileira. Neste particular, se apropriando de conceitos de escola de tempo integral, escola de formação integral e escola holística, constrói-se um elemento desafiador, a proposição de se pensar um projeto novo para a educação baseado na formação integral do ser humano contemplando uma perspectiva holística da educação.

\section{MICHAEL APPLE: O SENSO COMUM E A CONSTRUÇÃO DOS CONCEITOS IDEOLÓGICOS}

Apple, contemporâneo de uma época em que o capitalismo encontrou resistência nas lutas e na organização do proletariado, percebeu a importância do papel da escola e da educação para o avanço das conquistas sociais. Da mesma forma a compreendeu a importância da política como o campo de batalha dos grupos antagônicos na consolidação de suas posições frente ao controle social. Percebeu que cada injustiça cometida a uma minoria social organizada agregava um numero maior de militantes a causa do povo. Assim, junto com os trabalhadores, sindicatos e como docente se torna líder sindical e classista. Quando desenvolve os estudos de mestrado e doutorado percebe a contradição de a universidade estar próxima geograficamente dos bairros mais pobres de Nova York e ao mesmo tempo distante das pessoas. A contradição o faz desenvolver suas teorias sobre a sociedade, o poder e o currículo procurando desmistificar o papel dos operários, negros, latinos, mulheres, ou ainda, das minorias, de classe, gênero e raça que são manipulados a partir da construção de consensos para eliminar o conflito. Apple vê a importância da escola neste processo, mas também que a escola é um espaço onde se podem criar novas dinâmicas na produção de novas hegemonias.

A sociedade se move a partir da formação de blocos hegemônicos que se propõem a direcionar as pessoas a partir de suas leituras de mundo. Quando essas maiorias se formam, suas ideias passam a ser a vanguarda da sociedade e as ações construídas passam a representar este grupo. Os campos em disputa nestes casos são os que formam a infraestrutura social com a articulação do trabalho do professor, seu domínio do conteúdo, sua relação com a comunidade onde a escola está inserida. Contrapondo com a superestrutura que são as 
estratégias dos grupos que dominam a sociedade e se mantem do poder com o controle das ações que consolidam e perpetuam este poder como o currículo, a informação a ideologia. Segundo a teoria marxiana, a disputa pelo poder se encontra neste campo de batalha e para que ocorram mudanças é necessário:

\begin{abstract}
uma transformação massiva dos homens, o que só se pode realizar por um movimento prático, por uma revolução; que a revolução, portanto, é necessária não apenas porque a classe dominante não pode ser derrubada de nenhuma outra forma, mas também porque somente com uma revolução a classe que derruba detém o poder de desembaraçar-se de toda a antiga imundície e de se tornar capaz de uma nova fundação da sociedade. (MARX, 2007, p. 42)
\end{abstract}

As escolas são os espaços institucionais onde os movimentos práticos aconteçam, pois os agentes transformadores estão presentes. Por um lado se encontram os jovens, que por sua natureza contestam a ordem vigente e por outro se encontram os professores, que detém o controle da infraestrutura e fazem a relação de troca com a superestrutura do Estado controlado pelas classes detentoras do poder.

As propostas hegemônicas que se formam são resultado de um conjunto de pensamentos que partem do senso comum e se transformam numa ideologia que representa o pensamento político no determinado momento histórico. São fruto de uma série de elementos voláteis que se aglutinam e depois se esvaecem. Senso comum e ideologia representam um momento com características muito próprias e que podem ser desconstituídos e reconstruídos sobre novas bases.

Dentro desta forma de ler o mundo e a educação, Apple percebe que é importante analisar a escola dentro de uma nova perspectiva. Os conceitos até então utilizados não dão conta de responder as perguntas que se faz sobre 'como?' se ensina, como acontece o processo de educação é fundamentar o por quê? quem? qual? Ou seja, é fundamental entender quem são os beneficiários de determinada educação, de determinado conhecimento; que grupos detêm o protagonismo na escola: que grupos são beneficiados; qual a relação do que se ensina na escola com a vida da comunidade; por que se ensina esse conteúdo e não aquele; por que se ensina dessa forma e não de outra. As complexas relações percebidas o leva a repensar uma nova linguagem mesmo que seja utilizando as mesmas palavras mas resinificando as para este novo momento em que se está inserido. 
Assim vivemos em sociedades que avançam politicamente na construção de espaços de decisão coletiva e de sociedades que retrocedem em direção ao autoritarismo e individualismo.

Vários elementos entram na confecção da realidade, do senso comum, das ideologias. As ideias que compõem as ideologias saem do senso comum da sociedade. Essas ideias só se constituem por fazerem sentido, por serem significativas para o grupo. O senso comum é formado por várias ideologias permeadas de ideias do senso comum. Há uma conexão entre as ideologias dominantes e o senso comum da sociedade e se mantem assim até o momento em que são significativas para o grupo, construindo uma hegemonia. A hegemonia se forma quando há uma ideologia dominante, quando o discurso predominante do grupo social se torna dominante se mantem uma hegemonia até a configuração de uma nova forma de pensar. Portanto o senso comum e a ideologia estão ligados entre si e contextualizados a um período histórico. Senso comum, ideologia e hegemonia são elementos de uma mesma situação histórica, se constroem num processo de interação.

Fatos convergem ou são conduzidos a convergirem de forma que se consolidarem em hegemonias, de avanço social ou de retrocessos.

Apple na sua trajetória de vida percebeu a forma como as relações econômicas se desenvolviam e construíam suas hegemonias, percebeu por sua experiência de vida que quanto mais avançavam as conquistas sociais maiores dificuldades para se construir uma democracia era imposta pela classe opressora. Os golpes sociais, trabalhistas e econômicos se sucediam para evitar que os bem de capitais pertencentes a burguesia capitalista fosse partilhado entre os trabalhadores e que uma das únicas formas de socializar era através da educação, quando de poderia se apropriar do currículo das escolas e construir uma escola nova $^{3}$. O entrave, porém se dava a partir da aglutinação das forças de direita em torno de novas formas ou novos grupos que procuravam construir novos sensos comuns em tono de propostas neoconservadoras e neofundamentalistas.

\section{A NOVA DIREITA}

\footnotetext{
${ }^{3} \mathrm{O}$ conceito de escola nova reflete um espaço onde é fundamental a distribuição de conhecimento a diferentes tipos de classes de pessoas sem desenvolver rotulações sociais, de classe, de gênero, etc. é fundamental que se questione de quem é essa educação? A que grupo social pertence este conhecimento? E de acordo com o interesse de quem é que se transmite determinado conhecimento?
} 
No processo de construção de hegemonias na sociedade, alguns momentos são dominados por forças progressistas e noutros momentos por interesses conservadores.

Todo o estrato social tem o seu 'senso comum' e seu 'bom senso', que são no fundo, a concepção de vida e do homem mais difundida. Toda a corrente filosófica deixa uma sedimentação de 'senso comum': é este o documento de sua efetividade histórica. O senso comum não é algo rígido e imóvel, mas se transforma continuamente, enriquecendo-se com noções científicas e com opiniões filosóficas que penetram no costume. (GRAMSCI, 2001, p. 209)

A caracterização das forças de direita percebe-se um forte apelo aos elementos neoliberais, neoconservadores e neofundamentalistas. Estes grupos se articulam e constroem um conjunto de ideologias procurando conservar ou até, voltar a um momento em que as ideologias representem um tempo passado, construindo hegemonias que são facilmente controladas por seu caráter religioso ou conservador.

A conquista do poder político e social como ocorreu no Brasil, no início do século XXI, conduziu ao poder uma nova classe social, este fato provocou uma reação radicalmente oposta aos padrões que estavam em discussão até então. Ocorreu pela primeira vez na historia de nosso país a alternância no poder político o que fez com que os conceitos de educação puderam ser revistos. As articulações que levaram ao poder os trabalhadores desarticulou a militância que saiu das ruas e se institucionalizou, retirando seu poder de mobilização. Por outro lado todos que ficaram fora do poder institucionalizado passaram a se organizar e construir novas formas de controle e hegemonia. Esse processo desencadeou na articulação dos neoconservadores e neofundamentalista, primeiramente nas estruturas sociais da sociedade, nos movimentos populares, em alguns sindicatos e centrais sindicais e posteriormente nos novos partidos políticos que foram se constituindo neste período.

A base dessa nova articulação passa pelos espaços existentes, assim os maiores embates e as propostas de mudança mais rapidamente implementadas se encontram na educação. O primeiro debate que acontece envolve temas relacionados com os pontos elencados na construção do plano decenal de educação.

A principal polêmica que se debateu, tanto no Plano Nacional de Educação como nos Planos Estaduais e Municipais, ocorreram nas metas relacionadas ao combate à discriminação e a desigualdade de gênero. As discussões se intensificaram em 2014 com a aproximação do prazo limite para aprovação dos planos nas referidas esferas de poder. A resistência se deu principalmente pelas forças conservadoras que não se preocuparam com a exclusão de alunos 
do processo educativo. Esse fato mobilizou os ativistas de direita de praticamente todos os municípios onde o plano foi discutido de forma aberta e democrática pela sociedade. Neste sentido em várias câmaras políticas espalhadas pelo Brasil iniciou-se um debate sobre a implantação de uma 'escola sem partido' o que de forma inédita se fez a aprovação de um projeto neste sentido no estado de Alagoas.

Seus idealizadores defendem que na escola atualmente

A doutrinação política e ideológica em sala de aula ofende a liberdade de consciência do estudante; afronta o princípio da neutralidade política e ideológica do Estado; e ameaça o próprio regime democrático, na medida em que instrumentaliza o sistema de ensino com o objetivo de desequilibrar o jogo político em favor de um dos competidores.

Por outro lado, a exposição, em disciplina obrigatória, de conteúdos que possam estar em conflito com as convicções morais dos estudantes ou de seus pais, viola o art. 12 da Convenção Americana sobre Direitos Humanos, segundo o qual "os pais têm direito a que seus filhos recebam a educação religiosa e moral que esteja de acordo com suas próprias convicções."

Essas práticas, todavia, apesar de sua manifesta inconstitucionalidade e ilegalidade, tomaram conta do sistema de ensino. A pretexto de "construir uma sociedade mais justa" ou de "combater o preconceito", professores de todos os níveis vêm utilizando o tempo precioso de suas aulas para "fazer a cabeça" dos alunos sobre questões de natureza político-partidária, ideológica e moral. (ESCOLA SEM PARTIDO, 2016)

Assim se manifestam pela tomada de controle dos currículos das escolas. O poder de articulação das forças neoconservadoras e neofundamentalistas preparam o terreno de disputas pela educação fazendo intervenções pontuais no debate do Plano de Educação nas esferas municipais e estaduais, para no momento seguinte construir um projeto de lei com a finalidade de disputar os espaços políticos para a implantação de uma "Escola Sem Partido"4.

O único objetivo do Programa Escola sem Partido é informar e conscientizar os estudantes sobre os direitos que correspondem àqueles deveres, a fim de que eles mesmos possam exercer a defesa desses direitos, já que dentro das salas de aula ninguém mais poderá fazer isso por eles. .(ESCOLA SEM PARTIDO, 2016)

A estratégia intimidadora se resume em afixar nas escolas um cartaz com informações referente aos "Deveres do Professor" constando os seis itens as seguir que fazem parte do anexo do projeto de lei que se pretende aprovar nas câmaras municipais, nas assembleias estaduais e por fim no congresso nacional:

\footnotetext{
${ }^{4}$ Segundo os argumentos que estão expostos na página oficial da organização as escolas do país estão passando por uma doutrinação ideológica que ofende a liberdade do estudante e das famílias e que se faz necessário uma ação do Estado no sentido de alertar os profissionais da educação de que não cometam o crime de ferir as liberdades previstas na Constituição Brasileira nos artigos $1^{\circ}, 5^{\circ}$ e $206^{\circ}$.
} 
I - O Professor não se aproveitará da audiência cativa dos alunos, para promover os seus próprios interesses, opiniões, concepções ou preferências ideológicas, religiosas, morais, políticas e partidárias.

II - O Professor não favorecerá, não prejudicará e não constrangerá os alunos em razão de suas convicções políticas, ideológicas, morais ou religiosas, ou da falta delas.

III - O Professor não fará propaganda político-partidária em sala de aula nem incitará seus alunos a participar de manifestações, atos públicos e passeatas.

IV - Ao tratar de questões políticas, sócio-culturais e econômicas, o professor apresentará aos alunos, de forma justa - isto é, com a mesma profundidade e seriedade -, as principais versões, teorias, opiniões e perspectivas concorrentes a respeito da matéria.

V - O Professor respeitará o direito dos pais a que seus filhos recebam a educação religiosa e moral que esteja de acordo com suas próprias convicções.

VI - O Professor não permitirá que os direitos assegurados nos itens anteriores sejam violados pela ação de estudantes ou terceiros, dentro da sala de aula. (ESCOLA SEM PARTIDO, 2016)

Fica claro que a disputa se dá no campo político para se conseguir o controle do currículo. No período da Guerra Fria os movimentos sociais disputavam este espaço para construir uma sociedade includente, socialmente justa e para todos. Os avanços se davam no processo de ampliação dos espaços das minorias. Apple com sua experiência de vida, que posteriormente foi teorizada, fazia a defesa destas minorias e de como o currículo interferia nos avanços destas conquistas.

As escolas são locais de trabalho dos professores, algo que, com bastante frequência esquecemos. Entretanto, modificações na forma curricular, como as que discuti, tem um profundo impacto também sobre esse trabalho. Elas carregam uma relação fundamentalmente transformada entre trabalho, as habilidades, a consciência e os produtos de uma pessoa e os de outra pessoa. (APPLE, 1989, p. 47-48)

Para o movimento da "Escola Sem Partido" é fundamental que se pare com o processo de construção de uma escola democrática e inclusiva e se retorne ao individualismo liberal hoje transfigurado em neoliberal, este argumento se encontra na justificativa do projeto:

Diante dessa realidade - conhecida por experiência direta de todos os que passaram pelo sistema de ensino nos últimos 20 ou 30 anos -, entendemos que é necessário e urgente adotar medidas eficazes para prevenir a prática da doutrinação política e ideológica nas escolas, e a usurpação do direito dos pais a que seus filhos recebam a educação moral que esteja de acordo com suas próprias convicções. (ESCOLA SEM PARTIDO, 2016)

A força e a articulação dos movimentos de direita estão formando uma ampla aliança e disputando com sucesso o senso comum. Amplas camadas da sociedade passam a defender os ideais conservadores com argumentos que transitam desde o pensamento neofundamentalista liderado por correntes religiosas até argumentos econômicos puxados dela nova classe média neoconservadora. Estas forças se aglutinaram com certa rapidez e estão promovendo reformas sem que haja um debate que tencione para uma mudança tranquila e equilibrada. 
Na continuidade do processo de construção de uma nova hegemonia neoconservadora e neofundamentalista as articulações se fazem presente no processo de reestruturação do ensino médio. Embora se construísse um processo longo e demorado em torno da elaboração da Lei de Diretrizes e Bases da Educação Nacional e do Plano Decenal de Educação agora parece que as novas forças que se aglutinaram resolveram com toda a pressa do mundo propor uma nova peça organizada em uma medida provisória que tem um prazo de 120 dias para ser discutida e votada. As propostas não terão o tempo hábil para serem debatidas pela sociedade civil organizada em suas esferas de debates. Escolas, redes de ensino e universidades ficam fora do processo de construção em torno das propostas elaboradas pelo grupo que hoje se encontra a frente do Ministério de Educação. Mesmo que se convoque uma roda de debates e negociação o tema não será devidamente debatido e racionalizado. A apropriação da educação para beneficiar e privilegiar uma forma de educação que possivelmente não trará bons resultados para a inclusão de novos estudantes nas esferas acadêmicas seja elas de educação pesquisa ou extensão.

\section{A PROPOSTA DA ESCOLA SEM PARTIDO EM CONTRAPOSIÇÃO DA FORMAÇÃO INTEGRAL}

Conforme avançam as propostas de mudanças conservadoras na educação, a escola passa a ser entendida como um espaço de transmissão do conhecimento neutro e de preparação do estudante para a vida futura com informações necessárias para sua vida profissional e para se adaptar as mudanças tecnológicas que estão em processo. Desta forma, as gerações serão formadas a partir de um modelo focado num passado visto como perfeito e que respondia aos anseios das pessoas e num futuro idealizado em valores que preservem formas conservadoras onde o desenvolvimento de um pensamento autônomo, critico e a formação integral não tem espaço. A direita avança nos espaços sociais, econômicos e educacionais se escondendo atrás de conceitos idealizados e repassados para a sociedade através de construções teóricas do senso comum e divulgadas pelos órgãos de reprodução como a escola, a religião e a mídia tradicional e corporativa. Foi dentro deste espaço de múltiplas identidades e múltiplos interesses que as novas políticas da direita foram articuladas e ressurgiram de forma tão poderosa e agressiva para barrar os avanços propostos na educação pela esquerda democrática e popular. 
Tentando justificar questões morais e éticas, a proposta neoconservadora e neofundamentalista transferem o debate da formação integral e crítica dos estudantes para uma esfera religiosa e moralista. Os temas que debatem saúde, sexualidade, gênero são abolidos da escola em função de uma pseudo formação religiosa e moralista.

Por outro lado as questões que envolvem política, democracia e participação social são excluída das salas de aula em nome da desideologização do pensamento. Lutas de classe, exploração da mão de obra dos trabalhadores, direitos sociais não entram no debate por motivos que envolvem temas como o socialismo e o comunismo.

A articulação das forças neoconservadoras e neofundamentalistas estão desenvolvendo um debate a nível nacional sobre a questão da ideologização e da partidarização dos currículos nas escolas do país. O tema vem entrando na pauta de discussões no momento em que se radicaliza a discussão e os avanços que as propostas do campo popular e social ocorrem em várias instancias da sociedade brasileira. Após o resultado das eleições presidenciais que ocorreram no país em 2014 quando no segundo turno se configurou um debate ideológico vencido por um pequeno percentual de votos pelos movimentos de esquerda, os argumentos sobre a ideologização do currículo nas escolas aflorou com uma intensidade maior. O primeiro fato concreto ocorreu com a aprovação de uma lei "escola livre" no Estado de Alagoas provocando um grande debate nacional em torno do tema. Conforme a justificativa dos elaboradores da lei e publicados no sitio http://www.programaescolasempartido.org, para que demais parlamentares se utilizem dos argumentos para promoverem projetos de lei defendendo escola sem partido:

Percebesse o tom policialesco e de controle social a elaboração e a defesa de projetos dessa natureza. É preciso entender que toda a prática educativa tem seu viés político. A opção por determinado currículo ou por determinada forma de desenvolver um conteúdo em sala de aula tem uma conotação politica. Algumas ideologias, principalmente às de opção conservadora procuram esconder este fato e se apropriam da educação e, "a escola é utilizada como instrumento de expansão dos princípios neoliberais" (BALS, 2016, p 148). Desta forma, inibindo a liberdade de opção do professor se está inibindo a educação. A prática educativa se constrói a partir de uma dimensão política, na capacidade de convencimento e na apropriação dos instrumentos culturais, como afirma Saviani: 
potencializa (ou despotencializa) a sua prática política. E a dimensão educativa da política consiste em que, tendo como alvo os antagônicos, a prática política se fortalece (ou enfraquece) na medida em que, pela sua capacidade de luta ela convence os nãoantagônicos de sua validade (ou não-validade) levando-os a se engajarem (ou não) na mesma luta.

A dimensão pedag6gica da política envolve, pois, a articulação, a aliança entre os nãoantagônicos visando à derrota dos antagônicos. E a dimensão política da educação envolve, por sua vez, a apropriação dos instrumentos culturais que serão acionados na luta contra os antagônicos. (SAVIANI, 1999, p.94)

Desta forma se percebe que educação e política estão unidas e que se constroem no processo de superação de antagonismos que tem por finalidade o desenvolvimento social. A superação de situações de estagnação social ou de crises institucionais ocorrem com a superação de antagonismos. Historicamente se tem constatado que nos momentos que a sociedade exigia transformações para superar problemas a educação e a politica passaram a se articular no sentido de superar as barreiras impostas pela crise que enfrentavam. Se por um lado a política se esforçava para buscar ações efetivas para a construção de alternativas para o desenvolvimento educacional, a educação passava buscar condições subjetivas que possibilitasse o processo de discussões e da difusão de propostas políticas.

Educação e política mesmo atuando em campos distintos, mas muito próximos por seu processo social não podem estar afastados um do outro. Uma escola sem política produzirá um conhecimento inócuo, dissociado da sociedade e que produzira um conhecimento sem finalidade nenhuma. A educação tem a necessidade de discutir e aprofundar um conhecimento que respondas aos anseios da comunidade. $\mathrm{E}$ as ações políticas influenciadas por esse debate que ocorre na escola produzir ações que levem as pessoas a um novo patamar de cidadania.

Os neoconservadores e neofundamentalistas perceberam que era o momento de assumir o controle sobre da educação nacional, fortalecendo o debate sobre a "Escola sem Partido" e a possível mudança na educação no Brasil a partir de uma medida provisória que promovesse alterações na estrutura do Ensino Médio.

\section{A EDUCAÇÃO INTEGRAL/HOLÍSTICA ${ }^{5}$ FORMADORA DO SER HUMANO COMPLEXO}

\footnotetext{
${ }^{5} \mathrm{O}$ conceito "holismo" possui usualmente um significado referente a uma visão global. Aqui o termo tem o significado para a compreensão do conhecimento humano, e mais especificamente para a compreensão dos fenômenos de aprendizagem e educação. Uma educação que está voltada para o todo da educação, em uma
} 
$\mathrm{Na}$ esfera das discussões e teorizações de sociólogos, filósofos e pedagogos da atualidade se constroem teorias pedagógicas que envolvem o ser humano numa totalidade de vida e natureza. Segundo Edgar Morin,

O ensino deve conduzir a uma antropoética, dado o caráter ternário da condição humana, que é o de ser, ao mesmo tempo, indivíduo-sociedade-espécie. Neste sentido, a ética indivíduo-sociedade requer um controle mútuo da sociedade pelo indivíduo e do indivíduo pela sociedade, ou seja, pela democracia: no século XXI, a ética indivíduo-sociedade-espécie requer a cidadania terrestre. (MORIN, 2015)

Deve ser um ponto que transcende a formação humana para um patamar de complexidade que ira formar o homem novo. Um ser completo e complexo que se vê num mundo complexo e completo. A capacidade de transformar a realidade individual em uma realidade complexa esta a cada dia mais presente. Essa realidade se apresenta nas relações de solidariedade e responsabilidade que fazem pare da consciência do ser humano.

A educação integral e ou holística leva ao entendimento de que a pessoa é um todo complexo e ao mesmo tempo pode desenvolver uma capacidade de, a partir de sua autonomia adquirida pela formação integral fazer parte atuante dos processos de transformação que levarão a humanidade a um patamar novo de civilidade ${ }^{6}$ onde o ser humano tem a possibilidade de desenvolver todas as suas habilidades e conhecimentos.

Nós seres humanos precisamos de escolas que nos dotem para não perdemos nossas marcas de identidade, sentido de nossa existência, o saber manejar criticamente essa informação nebulosa, sem que nos deixemos de ser pessoas completas. Isso é o que sempre quis a educação integral e holística. (YUS, 2001)

Efetivamente Yus Ramos nos chama a atenção para a importância da escola e do currículo para nos constituir como seres humanos. A pessoa completa precisa de uma educação completa. Assim, não basta limitar conhecimentos ou tolher a liberdade e a democracia da escola para formar, é necessário ampliar e globalizar, não basta disciplinar é necessário transdisciplinar.

\section{REFLEXÕES E CONSIDERAÇÕES}

perspectiva de que, quando estudamos os fenômenos de criação de conhecimentos em um ser humano, este está interligado simultaneamente em suas várias dimensões (sensorial, racional, emotivo-afetiva, psicológica, espiritual-mítica, ética, comunitária e social).

${ }^{6}$ Civilidade aqui é entendida como o aprimoramento das relações desenvolvidas pela sociedade para atingir um comportamento humano mais tolerante e humanizado onde as diferenças políticas, ideológicas, sociais são compreendidas e assimiladas de forma que não cause desconforto às pessoas. 
Conforme a afirmação de um dos atores protagonista do filme "Os Educadores"7 fazendo referencia a importância das revoluções, mesmo as que não deram certo afirmou: "Sim, mas de todas as revoluções que ocorreram ficou claro que apesar terem fracassado as melhores ideias sobreviveram." (OS EDUCADORES, 34'45") . Da mesma forma podemos nos referir a educação dentro deste enfoque que abordamos ao elaborar este artigo. O processo para a construção de um modelo educacional que contemple de forma democrática e integral o ser humano é cheio de avanços e retrocessos.

A educação tradicional baseada no modelo cartesiano que predomina o modelo educacional no mundo ocidental se estabeleceu a partir de uma série de paradigmas e de um currículo que tem como base uma educação burguesa, voltada para o modo de produção capitalista industrial e que parte do pressuposto de que a sociedade é fragmentada, a educação deve ser moldada em fragmentos representados pelos diversos componentes curriculares onde se concentram saberes fragmentados e separados, construindo assim um ser humano individualizado e fragmentado preparado para desempenhar um papel especifico dentro do conjunto da sociedade.

Apple estudando a educação no pós-segunda guerra, percebeu a força do argumento e da estratégia neoconservadora predominante principalmente nos Estados Unidos e associada ao pensamento neofundamentalista, buscou elaborar uma forma de contestar estas forças a partir da articulação dos movimentos sociais, dos professores nas escolas e de pesquisadores, no sentido de ocupar as escolas e os currículos com uma educação voltada as classes dominadas, voltada as minorias, as questões de gênero, as questões que defendem uma sociedade inclusiva para todos. Nesta linha se contrapõe de forma revolucionaria e radical a proposta da cultura educacional tradicional e mecanicista que defende o liberalismo e as ideias fundamentalistas que procuram um controle social dentro e fora da escola. Na sua obra 'Educando à Direita' (2003) ele nos revela toda essa perversidade proposta para a defesa dos valores econômicos defendidos pelos grandes capitalistas que dominam o capital financeiro e industrial na atualidade, juntamente com os fundamentalistas religiosos que necessitam manter sua dominação a partir de lógicas e racionalidades duvidosas que predominas nas camadas médias da sociedade. Assim argumenta Apple que a educação utilizada por estes

\footnotetext{
${ }^{7}$ Die Fetten Jahre sind vorbei (no Brasil e em Portugal, Os Educadores) é um filme teuto- austríaco de 2004 escrito e dirigido pelo diretor austríaco Hans Weingartner. Foi indicado à Palma de Ouro como melhor filme de 2004 no Festival de Cinema de Cannes.
} 
segmento é vista como um instrumento para obtenção de suas metas econômicas e politicas de dominação.

Como reação a essa investida neoconservadora, neoliberal e neofundamentalista os movimento populares passaram a conquistar politicamente sistemas educacionais e passaram a implantar nestes espaços experiências voltadas a ampliação do projeto da população menos favorecida pelas demandas capitalistas. No caso brasileiro, a educação passa a ser discutida e implementada a partir de projetos como o Pibid - Programa Institucional de Bolsas de Iniciação à Docência, com o objetivo de valorização e formação de professores para atuarem na educação básica; como Pacto - Plano Nacional pelo Fortalecimento do Ensino Médio, com o objetivo de articular e coordenar ações na formulação de políticas para elevar o padrão de qualidade do Ensino Médio brasileiro. Estes dois projetos desenvolveram ações estratégicas e articuladas para o desenvolvimento das escolas e para organizar um novo redesenho do currículo, expressos desta forma:

O objetivo do ProEMI é apoiar e fortalecer o desenvolvimento de propostas curriculares inovadoras nas Escolas de Ensino Médio, buscando garantir a formação integral com a inserção de atividades que tornem o currículo mais dinâmico, atendendo as expectativas dos estudantes e às demandas da sociedade contemporânea.

As ações propostas devem contemplar as diversa áreas do conhecimento a partir de atividades propostas nos seguintes macro campos: Acompanhamento Pedagógico (Linguagem, Matemática, Ciências Humanas e Ciências da Natureza); Iniciação Científica e Pesquisa; Leitura e Letramento; Línguas Estrangeiras; Cultura Corporal; Produção e Fruição nas Artes; Comunicação, Cultura Digital e uso de Mídias; e Participação Estudantil.

Estas ações são incorporadas gradativamente ao currículo, ampliando o tempo na escola, na perspectiva da educação integral e, também, a atividade de práticas de atividades pedagógicas de modo que estas, de fato, qualifiquem os currículos das escolas de Ensino Médio. (PROEMI, 2012)

Gaudêncio Frigotto, já na década de oitenta no século passado afirmava que "A escola politécnica é posta como a escola da sociedade futura." (FRIGOTTO, 1989) Fazendo referencia que a escola precisa ser democrática e que deve existir dentro dela o debate político que defenda os interesses das pessoas que mais precisam da educação para conquistarem sua cidadania.

O avanço desta perspectiva está condicionado ao movimento de correlação de forças externas e internas à escola. Num e noutro caso demanda a ampliação de formação de quadros de intelectuais progressistas politicamente compromissados com a luta e interesse da classe trabalhadora, teórica e tecnicamente instrumentalizados não apenas para entender a realidade na sua complexidade e diversidade, mas principalmente para transforma-la. (FRIGOTTO, 1989, p. 253) 
A construção de uma escola integral holística está inserida neste contexto elaborado a partir de um acumulo de conhecimentos e propostas pedagógicas desenvolvidas pela humanidade e que foram sendo acumuladas pela sociedade e que no momento em que vivemos esta em disputa. A disputa pelo currículo requer uma atitude de, enquanto classe, nos posicionarmos por uma educação que forme o homem como um ser único e total, dentro de uma classe trabalhadora tem a pretensão de construir um mundo igualitário e preocupado em resgatar os princípios da democracia como afirma Edgar Morin: “A regeneração democrática supõe a regeneração do civismo, a regeneração do civismo supõe a regeneração da solidariedade e da responsabilidade.” (MORIN, 2005)

Assim, é o momento de propormos uma nova forma de ver e de ser escola. Uma escola que responda as necessidades da sociedade e de seus jovens, uma escola que contemple a formação intelectual, que possibilite acesso a cultura, a práticas de cultivo do corpo e do espirito, que possibilite o desenvolvimento do ócio, que desenvolva as emoções, uma escola que contemple os novos paradigmas da humanidade: uma escola integral e holística.

\section{BIBLIOGRAFIA}

APPLE, Michael W. Educando à Direita: Mercados, Padrões, Deus e Desigualdade. Instituto Paulo Freire. São Paulo: Cortez, 2003.

APPLE, Michael W. Educação e Poder. Porto Alegre: Artes Médicas, 1989.

BALZ, Ângela. O Neoliberalismo no Brasil e Algumas Consequências na Educação. In: SCHÖNARDIE, Paulo Alfredo; PILLATT, Líbera Raquel Bolzzan; SILVA, Sidinei Pithan da. Sociedade Brasileira e Educação: Olhares interpretativos. Ijuí: Ed. Unijuí, 2016.

ESCOLA SEM PARTIDO. Disponível em: www.programaescolasempartido.org/saiba-mais/, Acessado em 07 de out. 2016.

ESCOLA SEM PARTIDO. Disponível em: http://www.programaescolasempartido.org/ anteprojeto-estadual, Acessado em 11 de out. 2016.

FRIGOTTO, Gaudêncio. A Produtividade da Escola Improdutiva: um (re)exame das relações entre educação e estrutura econômico-social capitalista. São Paulo: Cortez, 2010.

GRAMSCI, Antonio. Cadernos do Cárcere. Volume 2. Rio de Janeiro: Civilização Brasileira, 2001.

MARX, Karl. A Ideologia Alemã: Crítica da mais recente filosofia alemã em seus representantes Feurbach, B. Bauer e Stirner, e do socialismo alemão em seus diferentes profetas. São Paulo: Boitempo, 2007.

MINISTÉRIO DA EDUCAÇÃO. Disponível em: http://pactoensinomedio.mec.gov.br/ images/pdf/port_971_09102009.pdf, Acesso em 27 de nov. 2016. 
MINISTÉRIO DA EDUCAÇÃO. Disponível em: http://portal.mec.gov.br/index.php?option= com_docman\&view=download\&alias=9864-rceb002-12\&Itemid=30192, Acesso em 27 de nov. 2016.

MORIN, Edgar. Ensinar a Viver. Manifesto para mudar a educação. Porto Alegre: Meridional/Sulina, 2015.

Edgar. Os Sete Saberes Necessários à Educação do Futuro. São Paulo: Cortez; Brasília, DF: UNESCO, 2005.

SAVIANI, Demerval. Escola e Democracia: teoria da educação, curvatura da vara, onze teses sobre educação e política. Campinas: Autores Associados, 1999.

YUS RAMOS, Rafael. Educação Integral: Uma educação holística para o século XXI. Porto Alegre: Artmed, 2002. 